\title{
Measures of obesity and accepted cardio-metabolic disease risk factors from a peri-urban female farm working population in South Africa
}

Shehan Randeria

Stellenbosch University

Danzil Joseph

Stellenbosch University

Ilze Lauren Mentoor

Stellenbosch University

Theo Nell ( $\nabla$ tnell@sun.ac.za )

Stellenbosch University https://orcid.org/0000-0003-3905-827X

\section{Research article}

Keywords: Adiposity, cardiovascular disease, visceral adiposity index, inflammation, dyslipidaemia

Posted Date: September 26th, 2019

DOI: https://doi.org/10.21203/rs.2.15201/v1

License: (9) (1) This work is licensed under a Creative Commons Attribution 4.0 International License. Read Full License 


\section{Abstract}

Background: Cardiovascular diseases (CVD) remains a primary cause of (central) obesity-associated mortality among African populations. Measures of adiposity are reported as prevalence's in a South African (SA) female farm working population at risk for cardio-and metabolic disease related to body mass index, (BMI), waist-to-hip ratio (W:H), waist circumference (WC) and visceral adiposity index (VAl), biochemical and metabolic blood parameters.

Methods: A cross-section of female farm workers $(n=120)$ from the Boland region in SA between the ages 20-60 years were recruited and classified according to different anthropometric indices including BMI, W:H, WC and the VAl, and subsequently divided into normal-and at risk groups for each index. Blood samples were analysed for inflammatory markers, serum insulin, glucose and a full lipid profile.

Results: Prevalence's and significant differences for the different adiposity measures between normal and overweight groups were: (BMI: $25.8 \%$ - $74.2 \%$; p<0.0001); (W:H: 57.5\% - 42.5\%; p<0.0001); (WC: 42.0\% vs 58.3\%; $p<0.0001)$; and (VAl: 48.3\% vs 51.7\%; $p<0.0001)$. Systolic blood pressure ( $<<0.01$ ) and diastolic blood pressure $(p=0.03)$ were different within the BMI grouping, as well as VAT\% $(p<0.001)$ and SAT\% $(p<0.01)$.

Differences were reported for body mass, BMI, WC and VAI within the W:H and WC groupings. Systolic $(p=0.04)$ and diastolic blood pressure ( $p=0.0009)$ were different in the WC grouping. Metabolic healthy and unhealthy women showed differences in BMI $(p<0.05) ; W: H(p<0.0001)$; WC $(p<0.0001)$. Systolic and diastolic blood pressure were different between metabolic healthy $(p<0.05)$ and unhealthy women $(p=0.0005)$.

The inflammatory cytokines were similarly elevated in the normal and obese groups TNFa; $(p<0.0001)$; IL-6; $(p<0.01)$, MCP-1; ( $p=0.0001)$, and resistin; $(p<0.0001)$. For the $W: H, I L-6(p<0.01)$ and blood glucose $(p=0.006)$ were different. The WC grouping showed differences in resistin $(p<0.0001)$, MCP-1 $(p<0.0001$, blood glucose $(p<0.01$, and insulin $(p=0.0002)$. For metabolic healthy vs unhealthy women, resistin $(p<0.0001)$; MCP-1 ( $p=0.0007)$; blood glucose $(p<0.01)$ and insulin $(p<0.05)$ were different.

Conclusion: Women suffering from obesity showed a higher pro-inflammatory profile and higher risk for cardio-metabolic disease using the BMI as a measure of adiposity compared to WC, W:H and VAl.

\section{Background}

Obesity remains a public health problem due to comorbidities such as diabetes, atherosclerosis, hypertension, and increased cardiovascular disease [1-4]. Global urbanisation and nutrition transition have aggravated a cluster of lifestyle related diseases [5-7]. South Africa forms part of global developments spurring non-communicable disease progression. A high prevalence of the metabolic syndrome, obesity and related metabolic complications experienced among South African populations, can be attributed to an urbanisation-mediated nutrition transition [6, 8-10].

The ramifications of "modern day living" has permeated both industrialised and developing countries, manifesting in a lifestyle characterised by excess caloric intake $[11,12]$. Adopting a more westernized lifestyle has contributed to an increase in the incidence of obesity and other lifestyle-associated comorbidities [13]. Obesity foreshadows various unfavourable cardiovascular outcomes such as hypertension, insulin resistance, diabetes and atherosclerosis [14]. Even though the association between obesity and CVD is well established, the site of fat accumulation in humans can have a fundamental role in the development and progression of these health risks.

Obesity is a phenotypical state characterised by the presence of excess adipose tissue mass and is linked to an unhealthy and unfavourable metabolic blood profile [15, 16]. Adipose tissue constitutes a dynamic, active multi-depot endocrine organ [17]. During an obese state, normal adipogenesis is compromised resulting in the production of hypertrophied and dysfunctional adipocytes that contribute to a chronic state of low grade inflammation [18, 19].

A low-grade inflammatory state is facilitated by elevated levels of pro-inflammatory cytokines and other inflammatory markers within circulation via an inflammatory response within white adipose tissue (WAT) itself $[20,21]$. Concurrently, there is a downregulated expression of anti-inflammatory proteins such as interleukin 10 (IL-10) and adiponectin [20-22]. This inflammatory process extends across other physiological systems through abnormal activation of immune cells [23].

The presence of visceral adipose tissue (VAT) distribution facilitates a primary role in obesity-induced inflammation. Visceral fat is associated with insulin resistance, diabetes, dyslipidaemia, high risk of atherosclerosis, and evidently increased mortality [24-26]. Gluteo-femoral obesity is linked to better insulin sensitivity and a decreased risk of developing dyslipidaemia, type 2 diabetes and atherosclerosis relative to elevated risks accompanying central obesity [2729].

Evidence suggests that BMI is considered inferior and an inadequate measure to assess adiposity as well as the role of adiposity in disease risk and mortality $[30,31]$. Lifestyle associated diseases are often associated with increases in adiposity, however this is more so attributed to the distribution of adipose tissue mass and the related extent of adipose tissue dysfunction than the quantity of adipose tissue per se [32]. This concept aligns with the metabolically-healthy phenotype often observed in overweight- or obese- individuals [33-35]. A classification that relies on BMI may not be a disputable representation of an individual's metabolic profile [34], where dysfunctional adipose tissue contributes to dyslipidaemia, insulin resistance, hypertension, hypercoagulability, and low-grade inflammation [21, 22].

Cardiovascular diseases (CVD) remains a primary cause of visceral adipose tissue-associated mortality among African populations [36, 37]. Central obesity poses a prominent risk to individual's cardio-metabolic health, independent of overall obesity and is associated with a greater risk of metabolic disease and subsequent mortality comparative to peripheral fat depots [38-41]. 
Several indices of visceral obesity have been established with much debate surrounding which anthropometric measure(s) is the most accurate and reliable predictor of CVD risk. Body mass index, waist-to-hip ratio (W:H), and waist circumference (WC) provide crude estimates of adiposity, and provide important indices relating to the dynamic interplay between both general and central obesity and various CVD risk factors [42]. The gender-specific visceral adiposity index (VAI) includes both anthropometric (WC, BMI) as well as metabolic (triglyceride (TG) and high-density lipoprotein cholesterol (HDL-C)) parameters in order to reflect both the extent of VAT distribution and adipose tissue dysfunction [26]. This index is considered a reliable indicator of visceral fat function associated with cardio-metabolic risk.

An investigation into these measures will provide valuable insight on the obese phenotype and the associated cardio-metabolic profile of such a demographic, specifically with regards to CVD and subsequent prevention and/or intervention. We therefore describe and compare the prevalence and extent of CVD risk in relation to BMI, W:H, WC and VAl, biochemical and metabolic blood parameters in a female farm working population in South Africa.

\section{Methods}

2.1 Ethics statement

Ethical clearance was obtained from Stellenbosch University's Health Research Ethics Committee I (HREC I) (protocol number N13/04/052).

\subsection{Study design and setting}

During March-July 2015, farmworkers from three wine estates (Villiera Wine Estate at the Owethu Clinic, Neethlingshoff Wine Estate, and Solms-Delta Wine Estate (Franschoek) were recruited in a cross sectional design between March 2015 and July 2015.

\subsection{Study population}

This sub-study included $n=120$ female farm workers between the ages of 20 and 60 years whom formed part of a larger farm worker study performed during 2015 [43]. During each site visit, experimental procedures were communicated with an opportunity to address any questions about the study. Written informed consent was obtained followed by assigning unique numbers to all data collection tools and laboratory analyses. Following laboratory analyses, individual feedback sessions were arranged to all volunteers at the respective data collection sites. The population of women included in the current study were risk classified either as normal/healthy or obese/unhealthy groups according to BMI, W:H, WC and VAl indices and/or cut-offs.

2.4 Data collection

\subsubsection{Anthropometrical assessments}

Anthropometrical measurements were performed in duplicate according to the International Society for the Advancement of Kinanthropometry (ISAK) standards [44]. Body mass (kg) was measured using a Seca 634 automatic scale (Seca, United Kingdom, Birmingham, England) to the nearest $0.1 \mathrm{~kg}$. Height (m) was measured using a portable stadiometer (Leicester ${ }^{\mathrm{Tm}}$; Leicester, England), assuming the Frankfort plane, to the nearest $0.1 \mathrm{~cm}$. The BMI (kg/ $\mathrm{m}^{2}$ ) was calculated using these base measurements (Equation. 1). Waist circumference (measured at the level midway between the lowest rib and the iliac crest) and hip circumference (measured at the widest diameter over greater trochanters) were assessed to the nearest $0.1 \mathrm{~cm}$ using a Lufkin tape measure (Lufkin, USA), and the W:H (Equation. 2) was subsequently calculated using these measures.

[Due to technical limitations, this equation is only available as a download in the supplemental files section.]

The VAl of each participant was subsequently calculated using the following measures; BMI, WC, TG levels and HDL-c levels (see Equation 3) [26].

[Due to technical limitations, this equation is only available as a download in the supplemental files section.]

\subsubsection{BMI classification}

Participants were classified as either being (i) normal weight $\left(<25 \mathrm{~kg} / \mathrm{m}^{2}\right)(\mathrm{n}=30)$, or (ii) overweight $\left(\geq 25 \mathrm{~kg} / \mathrm{m}^{2}\right.$ and $\left.<30 \mathrm{~kg} / \mathrm{m}^{2}\right)(\mathrm{n}=90)$, based on population and country-specific BMI cut-off values [45].

\subsubsection{W:H ratio}

Here, participants were categorized into two main risk groups; (i) normal W:H $(\leq 0.8)(n=69)$, and at risk W:H for CVD $(>0.8)(n=51)[46]$.

\subsubsection{Waist circumference}

The WC cut-offs for normal $(\leq 80 \mathrm{~cm})(\mathrm{n}=50)$ and overweight/centrally obese $(>80 \mathrm{~cm})(\mathrm{n}=70)$ women were designated according to the International Diabetes Foundation [1, 47].

2.4.5 Visceral adiposity index

The assumption was made that the regression constants were comparable to the current sample. Using cut-off values [48], participants were classified as either being (i) "metabolically healthy" (VAI <1.59) $(n=62)$ indicative of healthy non-obese subjects with normal adipose distribution (i.e. not centrally obese) and normal TG and HDL-C levels [26], or (ii) "metabolically unhealthy" (VAI $\geq 1.59)(n=58)$. 
2.4.6 Bio-electrical impedance analysis

Volunteers were informed on a pre-test protocol for Bio-electrical impedance analysis (BIA). The measurements were performed using the multi-frequency Bioscan 920 II analyser (Maltron 920, UK), to quantify \% visceral adipose tissue (VAT) and \% subcutaneous adipose tissue (SAT).

\subsubsection{Blood pressure}

Stationary blood pressure measurements were recorded in duplicate on the right arm, using a calibrated aneroid sphygmomanometer (Erka Perfect Aneroid 48, Germany), and stethoscope (Littmann 3M stethoscope, USA) with an appropriate cuff size.

2.4.8 Blood sampling and analysis

Blood sampling were performed from the cubital vein of the right arm using aseptic techniques into different blood collection tubes by a registered phlebotomist.

Two serum separation tubes (SST) were allowed to clot for 10 to 15 minutes at room temperature $\left(22^{\circ} \mathrm{C}\right)$ and centrifuged at 4000 revolutions per minute for ten minutes. Two ethylenediaminetetraacetic acid (EDTA) tubes were similarly centrifuged at $4^{\circ} \mathrm{C}$. Serum and plasma were aliquotted into Eppendorf tubes and immediately placed on dry ice and then transferred to a $-80^{\circ} \mathrm{C}$ bio freezer until analysis. Fasting blood glucose, insulin and a full blood lipid profile (TC, LDL-C, HDL-C, TG and non-HDL-c), were assessed by the local PathCare laboratory.

2.5 Laboratory analysis

All analyses were performed according to the manufacturer's protocols and specifications. MCP-1 was analysed as part of an 8-plex cytokine microplate and read on the Magpix plate reader (Luminex Corporation, 2006).

To quantify TNF-a, IL-6 and IL-10 the MILLIPLEX ${ }^{\circledR}$ MAP Human Cytokine / Chemokine Magnetic Bead Panel (\#HCYTOMAG-60K) was used and read on the Bio-Plex 200 plate reader (Bio-Rad, 2016).

\subsection{Statistical analysis}

Statistical analysis was performed using GraphPad Prism version 7.0 (GraphPad Software, Inc., United States of America). Normality was assessed using the Shapiro-Wilk test. Data are reported as means \pm standard error of the mean (SEM) for normally distributed values, or medians and interquartile ranges (IQR) for not normally distributed data. The student t-test (normally distributed), or Mann-Whitney U test (not normally distributed) were employed to report differences between the two groups. Statistical significance was accepted at $p<0.05$.

\section{Results}

3.1 A summary of the prevalence's based on the different classification of adiposity is provided in Table 1.

\subsection{Differences between anthropometric indices}

\subsubsection{The BMI}

Significant differences were observed between normal and overweight groups for W:H (0.75 \pm 0.01 vs $0.80 \pm 0.01, \mathrm{p}<0.0001)$; WC (70 [67.1 - 73.5] vs 87.6 [80.8 - $97.3 \mathrm{~cm}$ ], $\mathrm{p}<0.0001)$, and VAl (1.02 [0.68 - 1.54] vs 1.95 [1.23 - 3.11], $\mathrm{p}<0.0001)$ (Table 2). Additionally, significantly higher systolic blood pressure (140.0 [120.0 - 150.0] vs 130.0 [110.0 - $140.0 \mathrm{mmHg}], \mathrm{p}=0.01)$, and diastolic blood pressure (84.00 [80.00 - 90.00] vs 80.00 [70.00 $-90.00 \mathrm{mmHg}], \mathrm{p}=0.003) \mathrm{was}$ observed for overweight participants relative to normal weight females. Overweight women also presented with higher VAT\% (71.3 \pm 0.7 vs $61.5 \pm 0.9 \%, p=$ $0.001)$, and lower SAT\% (28.7 \pm 0.7 vs $38.5 \pm 0.9 \%, p=0.001)$.

\subsubsection{Waist-to-hip ratio}

Women at risk for CVD showed significantly higher body mass (83.5 $\pm 3.1 \mathrm{vs} 71.0 \pm 2.0 \mathrm{~kg}, \mathrm{p}<0.001)$. Significant differences were reported for BMI (26.7 [23.7 27.4] vs 31.0 [27.4 - $37.6 \mathrm{~kg} / \mathrm{m}^{2}$ ], $\left.\mathrm{p}<0.001\right) ; \mathrm{W}: \mathrm{H}(0.74$ [0.71 - 0.77] vs 0.85 [0.82 - 0.89], $\mathrm{p}<0.0001)$; WC (76.5 [71.4 - 84.5$]$ vs 90.0 [84.0 - $\left.\left.106.0 \mathrm{~cm}\right], \mathrm{p}<0.0001\right)$, and VAI (1.32 [0.81-1.82] vs 2.47 [1.45-3.42], p<0.0001) (Table 2). No differences were observed for SBP, DBP, and visceral and subcutaneous fat compartments (Table 2).

\subsubsection{Waist circumference}

Women who were classified as central obese showed higher body mass (86.5 [74.8-95.5] vs, 60.4 [53.9-69.1 kg], p<0.0001). Similarly, these women showed higher BMI (32.7 [28.9-38.6] vs 24.4 [22.3-26.3 kg/m²], p<0.0001), W:H (0.82 [0.77-0.86] vs 0.74 [0.71-0.77], p<0.0001), WC (89.9 [84.5-101.3] vs 72.6 [68.3 $-75.9 \mathrm{~cm}], \mathrm{p}<0.0001), \operatorname{VAl}(2.4$ [1.4 -3.3] vs 0.9 [0.7-1.6], $\mathrm{p}<0.0001$. Both SBP and DBP were higher $(140.0$ [120.0-156.3] vs 130.0 [120.0 - $140.0 \mathrm{mmHg}], \mathrm{p}=$ 0.004), (90.00 [80.00-98.5] vs 80.00 [70.00 - $90.00 \mathrm{mmHg}$ ], $\mathrm{p}=0.0009)$ (Table 1) in central obese women compared to normal cut offs. No differences were reported for VAT \% and SAT \% between groups in this classification (Table 2).

3.1.4 Visceral adiposity index 
Metabolically unhealthy women presented with higher general adiposity $\left(30.1[27.1-37.0]\right.$ vs $27.0\left[24.0-32.5 \mathrm{~kg} / \mathrm{m}^{2}\right]$, $\left.\mathrm{p}<0.005\right)$. The W:H also showed a higher risk for metabolically unhealthy women $(0.82$ [0.77-0.86] vs 0.75 [0.71-0.82], p<0.0001). Central obese women were classified as more unhealthy with WC (88.15 [82.25-100.50] vs 76.35 [71.55-86.15 cm], p<0.0001) relative to metabolically healthy women. Significant differences were also observed for SBP (140 [123-160] vs 130 [110 - $140 \mathrm{mmHg}, \mathrm{p}=0.0005)$, and DBP $(87$ [80-96] vs 80 [70 - $90 \mathrm{mmHg}$, $\mathrm{p}<0.05)$ between metabolically unhealthy versus metabolically healthy women respectively (Table 2 ).

3.2 Differences between measures of adiposity and blood lipids, glucose, insulin and inflammatory markers

With the exception of HDL-C, all blood lipids were significantly higher in at risk groupings of women across all adiposity measures (Table 3 ). A trend towards significance was noted for glucose in the W:H classification as well as TC within the metabolically unhealthy women (Table 3).

\subsubsection{BMI}

Overweight women displayed significantly higher TNF-a (7.95 [5.55 - 13.35 vs 4.12 [3.2 - $5.27 \mathrm{pg} / \mathrm{mL}], \mathrm{p}<0.0001)$, and IL -6 levels (0.81 [0.31-1.42] vs 0.18 [0.06- $0.46 \mathrm{pg} / \mathrm{mL}$ ], $\mathrm{p}<0.01$ ) compared to the normal range BMI group (Figure $1 \mathrm{~A} \& \mathrm{~B}$ ). A similar result was reported for resistin (7.57 [4.05 - 12.07$]$ vs 3.33 [2.59 - $3.70 \mathrm{ng} / \mathrm{mL}], \mathrm{p}<0.0001)$, and MCP-1 (12.00 [9.00 - 14.00] vs 7.50 [5.00 - $8.00 \mathrm{pg} / \mathrm{mL}], \mathrm{p}=0.0001$ ) (Figure $1 \mathrm{D} \& \mathrm{E})$. No significant differences were observed for IL-10 (Figure $1 \mathrm{C}$ ), fasting blood glucose and fasting insulin (Table 3) between the two BMI groups.

\subsubsection{W:H}

Here, IL-6 (0.91 [0.6 - 1.67] vs 0.31 [0.09 - $0.84 \mathrm{pg} / \mathrm{mL}], \mathrm{p}<0.01)$ (Figure $2 \mathrm{~A})$, and fasting blood glucose $(5.20$ [4.50-6.50] vs 4.60 [4.25-5.05 mmol/L], $\mathrm{p}=$ 0.006 ) were significantly higher in the at risk W:H group (Table 2). No differences were observed for MCP-1, resistin, TNF-a, IL-10 (Figure 2 ) and fasting insulin between groups.

\subsubsection{Waist circumference}

Women suffering from central obesity showed higher levels of resistin (9.99 [6.79-15.83] vs 3.65 [2.97-4.81 ng/mL], p<0.0001), and MCP-1 (0.13 [0.12$0.15]$ vs 0.08 [0.05-0.10 pg/mL], p<0.0001) (Figure $3 \mathrm{D}$ ). No significant differences were observed for TNF-a, IL-10 and IL-6 (Figure 3 ).

Women classified as central obese had significantly higher fasting blood glucose levels (4.90 [4.48-6.15] vs 4.55 [4.20-5.00 mmol/L], p<0.01), and insulin levels (18.25 [9.93-35.83] vs 10.05 [5.75-17.48 mIU/L], $\mathrm{p}=0.0002)$ (Table 2).

3.3.4 Visceral adiposity index

Metabolic unhealthy women showed higher levels for resistin (9.98 [6.75-17.65] vs 3.92 [3.04-8.50 ng/mL], p<0.0001), and MCP-1 (0.13 [0.12 - 0.14$]$ vs 0.08 [0.06-0.11 pg/mL], $p=0.0007$ ) (Figure $4 \mathrm{D} \& \mathrm{E}$ ). Additionally, women who were classified as metabolically unhealthy had significantly higher fasting blood glucose levels (4.90 [4.50-6.55] vs 4.55 [4.10-5.03 mmol/L], $\mathrm{p}<0.01)$ and lower insulin levels (12.55 [6.18-22.75] vs 16.65 [9.50-35.08 mIU/L], $\mathrm{p}<0.05)$ relative to metabolically healthy women (Table 2 ).

\section{Discussion}

Various anthropometrical indices/parameters related to the measurement of adiposity, including whole-body and central fat deposits, that is not limited to $\mathrm{BMI}$, are used in public health studies. This study aimed to describe the prevalence of cardio-metabolic risk factors in peri-urban female farmworkers based on different anthropometric risk indices including; BMI [45], W:H [46, 49], WC [47, 49] and VAI [48], and the role of metabolic and inflammatory markers for this female population.

\subsection{Prevalence}

A relatively high overweight prevalence is reported for all anthropometrical indices in this population, where more than half of the women are classified as both generally and centrally overweight, demonstrating current national and global upward trends in adiposity [50-53].

Abdominal obesity poses a major risk factor for CVD and other associated morbidities [4]. The findings from this study revealed that the prevalence of central obesity provided by cut-offs for W:H, WC and VAl, to be higher than the prevalence of overall obesity defined by BMI. Discrepancies in central and general adiposity prevalence results indicate that women may not be classified as being "overweight" (based on BMI cut-offs) [45], but may be at high cardiometabolic risk due to elevated central adiposity indices (based on WC, W:H and VAI) and exceeding respective "normal" cut-off values. It is thus also plausible that the BMI, as a more traditional and widely-established anthropometric measurement, may underestimate the true prevalence, and physiological connotations, of "obesity" in this population. At least in part, provided the extensive health complications associated with the presence of excessive abdominal or visceral fat.

Increased visceral fat, characteristic of a centrally obese phenotype, is more metabolically active than subcutaneous fat and has been shown to have more adverse health consequences than overall obesity $[38,39]$. Women with central obesity are at higher risk for the development of cardio-metabolic events such as CVD, hypertension and type-2 diabetes mellitus [36, 54].

In agreement to our study, a similar trend in prevalence has also been observed in other South African studies, further disputing the physiological credibility of BMI as a measurement of obesity. The Cardiovascular Risk in Black South Africans (CRIBSA) study reported $86 \%$ of women presenting with central obesity 
[38]. More recently, Owolabi, Ter Goon [55] reported similar prevalence rates of central obesity (67 \%) and W:H (58 \%), where the prevalence of central obesity remained prominent even in participants classified according to normal BMI cut-offs.

\subsection{Anthropometric and physiological parameters}

Significant differences were observed between normal and respective at risk groups for BM, BMI, W:H, WC and VAl irrespective of their anthropometric classification. The at risk group presented with significantly higher values relative to the normal-counterparts. Our results suggest that BMI may provide a satisfactory anthropometric tool in assessing central adiposity (defined by WC, W:H and VAI). An observation that is conflicting to previous research [30, 31]. However, it should be noted that despite the significant differences observed between normal and at risk women, the median BMI and VAI parameters for the normal W:H group and metabolically healthy VAI group were higher than normal BMI cut-off values $\left(<25 \mathrm{~kg} / \mathrm{m}^{2}\right)$ [45]. Consequently, the normal W:H group and metabolically healthy VAI group should, based on BMI classification criteria, be classed as overweight. Therefore, in retrospect this finding suggests, and consolidates the well reported notion, that BMI may not be a reliable anthropometrical estimation for central obesity [56, 57], and thus may not accurately reflect CVD health risks for this population. Particular in the case of VAI results, the above-mentioned results elucidate "healthy obesity".

Despite being classified as overweight or obese on the premise of established BMI cut-offs, these women are not deemed centrally obese or metabolically unhealthy.

Visceral adipose tissue (VAT\%) and subcutaneous adipose tissue (SAT\%)

From the significant differences observed between anthropometrical subgroups for VAT (\%) and SAT (\%), it is evident that BMI and W:H present a more accurate description of abdominal adipose tissue distribution, specifically within overweight subjects. However, in our study there are significant differences evident between normal and overweight BMI subgroups for both VAT (\%) and SAT (\%) data. The site-specific accumulation of body fat, either viscerally or subcutaneously, dictates the risk for the development of further health complications. The results observed for VAT (\%) and SAT (\%) were unable to distinguish between the two as both parameters presented with significant differences. In this regard, body composition results for BMI suggest that overweight females are both centrally (elevated VAT) and peripherally (elevated SAT) obese versus normal females, thus aligning with the consensus of BMI being a measurement of general adiposity.

Furthermore, the body composition results reported for BMI are in correspondence with the significant inflammatory profile expressed between BMI subgroups. Despite this, it is suggested that VAT secretes more inflammatory cytokines than SAT [58]. The elevated expression of inflammatory mediators has also been observed in VAT depots of people suffering from obesity $[37,39,59]$. This is particularly relevant given that the BMI subgroups also provided the most extensive inflammatory profile with regards to the significant differences observed for inflammatory markers.

By contrast, excess abdominal adipose tissue build-up has also been linked with the hypertrophy and dysfunctional expansion of SAT, which may also contribute to an enhanced inflammatory response [60]. Thus, in conjunction with VAT (\%) results observed in this study, [61] reported that high VAT levels were reciprocally indicative of elevated levels of both IL- 6 and TNF-a. Consequently, VAT establishes an inflammatory profile that harbours a greater predisposition for the development of cardio-metabolic diseases [38, 39, 41, 62]. Significant VAT (\%) and SAT (\%) results for BMI reflect the adverse inflammatory profile observed between normal and overweight BMI subgroups.

Blood pressure (SBP and DBP)

Studies propose that approximately $70 \%$ of hypertension risk can be attributed to the presence of excessive body weight [63-65]. Epidemiological studies showed that adiposity and hypertension are precursor factors for CVD development [66]. Blood pressure itself is a product of both cardiac output and peripheral resistance [14], and correspondingly increases with weight gain via the activation of homeostatic mechanisms such as the central nervous system and the renin angiotensin system. Additionally, physical compression of the kidneys by excessive visceral fat, ectopic fat and pararenal fat is also proposed to increase the risk of hypertension [66]. This perhaps further favours the tendency towards anthropometrical measures of central adiposity versus whole-body. However, statistical significance across all anthropometrical/obesity indices suggests that adiposity as a whole contributes to elevated blood pressure and may not be limited to site-specific adipose tissue deposition (i.e. whole-body $v s$ abdominal adipose tissue stores). Several studies report an independent association have found that between hypertension, obesity, TNF-a, and IL $-6[39,67]$. Which may in part contribute to the elevated blood pressure results observed across groups for all anthropometrical indices, particularly BMI subgroups. However, the inflammatory component relating to hypertension and its development reasons that elevated BP may be more inclined to central obesity, provided that intra-abdominal fat stores contribute more to inflammation. Stępień [68] reported no significant differences in the inflammatory markers, IL-6 and TNF-, when comparing obese normotensive and hypertensive subjects, thus disputing the independent and causative role of adipose tissue derived inflammation and related pro-inflammatory mediators in elevating blood pressure towards hypertensive levels.

Blood lipid profile

Dyslipidaemia has been strongly implicated in the onset and progression of cardio-metabolic diseases such as type 2 diabetes and the metabolic syndrome [69]. Dyslipidaemia is characterized by low concentrations of HDL-c and elevated levels of total cholesterol and triglycerides, specifically cholesterol-rich atherogenic lipoproteins molecules (such as VLDL-c and small dense LDL-c particles) [70-74]. This adverse dyslipidaemic blood lipid profile is evident in all "abnormally-classified" anthropometric groups of the study population and present with significantly different blood lipid levels than normal "healthy" women. Additionally, the respective blood cholesterol concentrations for "abnormal" anthropometric subgroups were elevated above normal ranges for healthy or normal blood cholesterol levels as classified by the IDF, the South African Heart Association (SA Heart), and the Lipid and Atherosclerosis Society of Southern Africa (LASSA) dyslipidaemia guidelines $[47,71]$. 
Dysfunctional adipose tissue is associated with excess adiposity and upregulate lipolysis that results in the release of free fatty acids (FFAs) into the blood. These FFAs are directed to the liver for a higher yield of TG and VLDL [75]. The higher output of this so called "bad cholesterol" and the parallel decrease in circulating "good cholesterol" (HDL-c) promotes the development of dyslipidaemia among obese people [72]. Therefore, it is possible to associate this complication with an increased risk of developing CVD [76]. Notably, elevated plasma cholesterol exceeding normal levels mediates changes in the permeability of the arterial endothelial resulting in the accelerated trans-endothelial passage of atherogenic bad cholesterol, particularly LDL-c particles, from the plasma into the intima of the arterial wall resulting in atherosclerosis $[77,78]$.

Notably, adverse blood lipid profile has been observed in several South African studies particularly with regards to its involvement with the metabolic syndrome [8, 38]. Reiger et al. [79] provided evidence in which the mean BMI was marginally higher in a dyslipidaemic population relative to non-dyslipidaemic participants. Similar to our findings, the dyslipidaemic subjects presented with a larger WC and W:H, which may in part explain the abnormal blood lipid levels observed in all "abnormally-classified" anthropometric groups. Similar to our findings for the VAl and WC normal and "unhealthy" groups, Peer et al. [8] reported high proportions of the female study population presenting with central obesity ( $86 \%$ ) and low HDL-c (75\%), proposing a high correlation and interrelationship between these two parameters. In agreement, this relationship is observed in the present study population between anthropometric subgroups.

Inflammatory markers

The inflammatory profile observed in our study population was more evident in the BMI anthropometric group. Notably, adipose tissue distribution is suggested to have a primary role in the pathophysiology of CVD and related cardio-metabolic complications by the site-specific adipose tissue production of inflammatory cytokines (pro- $v s$ anti-inflammatory) and mediators (i.e. adipose tissue macrophages) [80]. This result questions the impact of central adiposity with regards to its contribution towards a pro-inflammatory response. Specifically, in the case of BMI, the pro-inflammatory molecules (IL-6, TNF-a, resistin and $\mathrm{MCP}-1$ ) exhibited significant differences between anthropometric groups. Additionally, the BMI group provided the most significant differences with regards to the inflammatory parameters/markers despite its critique of being only an index for general adiposity.

The inflammatory results obtained for participants characterised as centrally obese by anthropometric indices, namely W:H, WC and VAl, may suggest that these women are "metabolically healthy" and obese despite exhibiting elevated levels of body fat, they portray no other metabolic complications and subsequently reduced levels of inflammatory molecules. Conversely, inflammatory results suggest that BMI presents in this population as a more sensitive anthropometrical index. The inflammatory profile observed between BMI groups is in accordance with evidence where significant differences were noted between normal and overweight groups [19, 81, 82].

IL-6 was increased in overweight/at risk groups for both BMI and W:H classifications. Studies comparing indices concur that individuals displaying a centrally obese phenotype present with a more adverse metabolic profile relative to general adiposity indices, this is clinically depicted by elevated levels of cytokines. A study by Park [81] showed that IL-6 is better associated with visceral obesity in obese subjects relative to BMI classifications.

Adipose tissue distribution is important in determining the inflammatory profile of overweight or obese individuals. Our data showed elevated VAT\% and SAT\% in the overweight/at risk groups when classified by $\mathrm{BMI}$ and $\mathrm{W}: \mathrm{H}$, along with the higher IL- 6 levels. The overweight BMI group presented with significantly elevated SAT \% and VAT \%, which propose that central obesity may be causally involved; either indirectly, or through the initiation of insulin resistance ( $v i a$ inflammatory mediators released from adipose tissue), to facilitate the development of hypertension and dyslipidaemia [38, 83, 84].

Monocyte chemoattractant protein-1 showed significant differences between all anthropometric groups of BMI, WC and VAl, suggesting immune cell (macrophage) recruitment, accumulation and subsequent infiltration. This is a characteristic feature of adipose tissue expansion and subsequent dysfunction which is evident in both general and central obesity indices $[85,86]$. With obesity and subsequent adipocyte enlargement, adipose tissue undergoes aberrant molecular and cellular changes. This results in the infiltration and accumulation of the pro-inflammatory M1 type macrophages within obese adipose tissue leading to a local inflammatory response $[87,88]$. The number of macrophages residing in adipose is also observed to markedly increase with the extent of obesity. This is presumed to be a means of eliminating or "clearing-out" apoptotic adipocytes85, 89]. However, macrophage infiltration and accumulation within obese adipose tissue extends beyond simply local inflammation but manifests in various other metabolic complications that is associated with obesity. The aberrant activation and phenotypic change (anti-inflammatory M2 to pro-inflammatory M1 type macrophages) of these immune cells results in a systemic inflammatory response. Additionally, the pathological interaction of macrophage accumulation and dyslipidaemia, both obesity-related dysfunctions, facilitate atherosclerotic plaque development within the arterial wall [85]. The enhanced migration of cholesterol-rich lipids (particularly LDL-c) into the arterial wall and the increased infiltration and adhesion of macrophages to the smooth muscle cells of the arterial wall produce a dynamic interplay that both initiate and enhance plaque formation [78]. Thus, it is likely that the inflammatory effects induced by obesity accelerate atherosclerosis [85].

The related increase in inflammatory adipokines reported in the studied anthropometric groups, particularly with regards to the adverse inflammatory profile present in overweight BMI groups, corroborates with evidence that suggests that inflammatory factors, such as IL-6 and TNF-a, produced and secreted by adipocytes can act on and activate monocytes in an endocrine-like manner [22, 85, 90-93]. In light of this, TNF-a derived from macrophages can act on adipocytes and mediate the production of inflammatory adipokines, to exacerbate pro-inflammatory conditions [94]. A paracrine and endocrine loop involving inflammatory factors between adipocytes and macrophages establishes a damaging cycle that aggravates inflammatory changes within adipose tissue facilitating further metabolic dysfunction [94]. This in part may explain the pro-inflammatory profile observed particularly in the overweight BMI groups. This result is further supported by significant VAT (\%) and SAT (\%) results, particular with regards to BMI [95].

In agreement with the BMI classification, the higher MCP-1 and resistin levels in the overweight individuals when classified based on WC and VAI further support a recognised consensus that current recommended obesity indices and related cut-off points attributed to African populations do not provide an adequate assessment of an individual's health status, particularly with regards to CVD risk. Consequently, our findings do not correspond with expected inflammatory profiles in centrally-obese women within the study population. 
Glucose and insulin data presented by anthropometric groups, specifically WC and VAI agree with corresponding inflammatory data and related crosssectional studies which demonstrated the increased presence of hyperinsulinemia and glucose intolerance amongst centrally obese subjects [24, 25]. Both WC and VAI exhibited significantly elevated fasting blood glucose and fasting blood insulin levels in overweight and metabolically unhealthy groups, suggesting the development of insulin resistance and/or type 2 diabetes mellitus [96-98].

The augmented release of inflammatory mediators, such as cytokines and adipokines have been observed in visceral adipose tissue stores of obese individuals. The enhanced expression of such inflammatory molecules has been implicated in the disturbance in insulin signalling, particularly via the inhibition of insulin receptor kinase activity $[99,100]$. Alternatively, both in vivo and in vitro studies showed that pro-inflammatory factors such as TNF-a and IL-6 can attenuate insulin-mediated uptake of glucose in peripheral tissues [99]. Insulin resistance is suggested to mediate abnormal lipid levels thus enhancing TAG and LDL-cholesterol concentrations [101].

\section{Conclusion}

The overall prevalence of adiposity, specifically central adiposity (W:H and WC), was found to be considerably high in this female farm-worker population. The $\mathrm{BMI}$, although not considered a true reflection of central adiposity and risk for CVD in this population, is the main index that showed significant differences among the majority of anthropometric assessments, inflammatory markers, serum insulin, glucose and lipid profile, and therefore provides the most promising index that indicates an increased risk for CVD within these women. All at risk groups favoured an unhealthy, or adverse blood lipid profile relative to normal groups, indicative of dyslipidaemia, a prominent risk factor and link in CVD and body fat gain. It is evident that BMI depicts an adverse cardio-metabolic profile relative to indices representative of central adiposity in this population. Despite this, significant body composition data in the BMI group, with regards to high levels of percentage VAT and SAT, suggests that central adiposity still poses an adverse role in enhancing CVD risk. Body mass index may be utilised as a tool to predict differences in body composition, physiological and biochemical parameters in the women of this study, and thus anticipate CVD risk.

The study highlights the cardio-metabolic burden as a consequence of higher obesity prevalence and emphasizes the need for on-going research into the epidemiological and health transition in this sample. Furthermore, we hope to add insight towards the development of ethnic-based definitions with clear and different cut-off values for Africans in order to curtail obesity prevalence and address the cardio-metabolic burden present within the women of this study through necessary public health interventions that focusses on physical activity and sustainable nutrition.

\section{Declarations}

\section{Ethics approval and consent to participate}

Ethical clearance was obtained from Stellenbosch University's Health Research Ethics Committee I (HREC I) (protocol number N13/04/052).

\section{Consent for publication}

All authors provide consent.

\section{Availability of data and material}

The data used for this study cannot be made available by the authors. We have to obtain ethical clearance and a statement in the consent form for volunteers to be aware of this. This was not the case so we cannot unfortunately provide data.

\section{Competing interests}

The authors have no competing interests.

\section{Funding}

The study was supported by grants from the Cancer Association of South Africa (CANSA) and the National Research Foundation (NRF) of South Africa. Funding bodies had no role in the study design, data collection, data analysis, interpretation of data and manuscript preparation.

\section{Authors' contributions}

TN conceptualized the study, was part of the fieldwork, analyzed the data and co-wrote the manuscript. SR, DJ and IM made substantial contributions to the study and interpretation of data and were involved in the drafting of the manuscript. All authors read and approved the final manuscript and agreed to be accountable for all aspects of the work.

\section{Acknowledgements}


The authors wish to thank all participants of the study, as well as all farm managers for granting access to the premises in order to execute this study. We would specifically like to thank Sr Samantha Adams and Sr Nina de Jager from the Owethu Clinic, Mr. Byron Langenhoven from the Pebbles Project at the Villiera wine estate for the direct link between the Integrated Metabolic Disease Research Group (IMDRG), and the volunteers. We would also like to thank Sr Anna Wium at Neethlingshoff wine estate, and the Solms-Delta Wine Estate trust manager, Mrs. Charlotte van Zyl, health care worker, Magdalene Davids and social worker Charnè Abrahams. Dr M Kruger as well as Sumine Marais, Olga Johnson, Camilah de Nobrega and Sinead Boshoff that were part of the data collection as part of their post graduate studies.

\section{Abbreviations}

Bio-electrical Impedance Analysis (BIA); Body Mass Index (BMI); Cardiovascular Diseases (CVD); Cancer Association of South Africa (CANSA); Cardiovascular Risk in Black South Africans (CRIBSA); Diastolic Blood Pressure (DBP); Ethylenediaminetetraacetic Acid (EDTA); Free Fatty Acid (FFA); High-density Lipoprotein Cholesterol (HDL-C); Interleukin 10 (IL-10); Interleukin 6 (IL-6); Interleukin 8 (IL-8); International Diabetes Federation (IDF); Interquartile Ranges (IQR); Lowdensity Lipoprotein Cholesterol (LDL-C); Monocyte Chemoattractant Protein-1 (MCP-1); National Research Foundation (NRF); Non-high-density Lipoprotein Cholesterol (Non-HDL-C); Serum Separation Tubes (SST); Standard Error of the Mean (SEM); Subcutaneous Adipose Tissue (SAT); Systolic Blood Pressure (SBP); Total Cholesterol (TC); Triglyceride (TG); Tumor-necrosis Factor Alpha (TNF-); Visceral Adipose Tissue (VAT); Visceral Adiposity Index (VAI); Waist Circumference (WC); Waist-to-hip Ratio (W:H); White Adipose Tissue (WAT)

\section{References}

1.Alberti, K. G. M. M., P. Zimmet, and J. Shaw, Metabolic syndrome-a new world-wide definition. A consensus statement from the international diabetes federation. Diabetic medicine, 2006. 23(5): p. 469-480.

2.Viana Abranches, M., et al., Obesity and diabetes: The link between adipose tissue dysfunction and glucose homeostasis. Nutrition research reviews, 2015. 28: p. 121-132.

3.Lovren, F., H. Teoh, and S. Verma, Obesity and Atherosclerosis: Mechanistic Insights. The Canadian journal of cardiology, 2015. 31: p. 177-183.

4.Barroso, T. A., et al., Association of central obesity with the incidence of cardiovascular diseases and risk factors. International Journal of Cardiovascular Sciences, 2017. 30(5): p. 416-424.

5.Okafor, C. I., The metabolic syndrome in Africa: Current trends. Indian journal of endocrinology and metabolism, 2012. 16(1): p. 56.

6.Young, F., et al., A review of co-morbidity between infectious and chronic disease in Sub Saharan Africa: TB and diabetes mellitus, HIV and metabolic syndrome, and the impact of globalization. Globalization and health, 2009. 5(1): p. 9.

7.Romieu, I., et al., Energy balance and obesity: what are the main drivers? Cancer Causes \& Control, 2017. 28(3): p. 247-258.

8.Peer, N., et al., High prevalence of metabolic syndrome in the Black population of Cape Town: the Cardiovascular Risk in Black South Africans (CRIBSA) study. European journal of preventive cardiology, 2015. 22(8): p. 1036-1042.

9.0ggioni, C., et al., Shifts in population dietary patterns and physical inactivity as determinants of global trends in the prevalence of diabetes: an ecological analysis. Nutrition, Metabolism and Cardiovascular Diseases, 2014. 24(10): p. 1105-1111.

10.Pradeilles, R., et al., Socio-economic influences on anthropometric status in urban South African adolescents: sex differences in the Birth to Twenty Plus cohort. Public health nutrition, 2015. 18(16): p. 2998-3012.

11.Rodríguez-Hernández, H., et al., Obesity and inflammation: epidemiology, risk factors, and markers of inflammation. International journal of endocrinology, 2013. 2013.

12.Mingrone, G. and M. Castagneto, The Pathophysiology of Obesity, in Minimally Invasive Bariatric and Metabolic Surgery. 2015, Springer. p. 17-23.

13.Twig, G., et al., Severe obesity and cardio-metabolic comorbidities: a nationwide study of 2.8 million adolescents. International Journal of Obesity, 2019. 43(7): p. 1391.

14.Zhou, J. and G. Qin, Adipocyte dysfunction and hypertension. American journal of cardiovascular disease, 2012. 2(2): p. 143.

15.Castro, A., L. Macedo-de la Concha, and C. Pantoja-Meléndez, Low-grade inflammation and its relation to obesity and chronic degenerative diseases. Revista Médica del Hospital General de México, 2017. 80(2): p. 101-105.

16.Kotsis, V., et al., Obesity, Hypertension, and Dyslipidemia. Obesity: Pathogenesis, Diagnosis, and Treatment, 2019: p. $227-241$.

17.Mechanick, J. I., S. Zhao, and W. T. Garvey, The adipokine-cardiovascular-lifestyle network: Translation to clinical practice. Journal of the American College of Cardiology, 2016. 68(16): p. 1785-1803.

18. Heilbronn, L., S. Smith, and E. Ravussin, Failure of fat cell proliferation, mitochondrial function and fat oxidation results in ectopic fat storage, insulin resistance and type I/ diabetes mellitus. International journal of obesity, 2004. 28(S4): p. S12.

Page $9 / 18$ 
19.Heinonen, S., et al., Adipocyte morphology and implications for metabolic derangements in acquired obesity. International journal of obesity, 2014. 38(11): p. 1423.

20.Skurk, T., et al., Relationship between adipocyte size and adipokine expression and secretion. The Journal of Clinical Endocrinology \& Metabolism, 2007. 92(3): p. 1023-1033.

21.Klöting, N. and M. Blüher, Adipocyte dysfunction, inflammation and metabolic syndrome. Reviews in Endocrine and Metabolic Disorders, 2014. 15(4): p. 277-287.

22.Blüher, M., Adipose tissue dysfunction contributes to obesity related metabolic diseases. Best practice \& research Clinical endocrinology \& metabolism, 2013. 27(2): p. 163-177.

23.Balistreri, C. R., C. Caruso, and G. Candore, The role of adipose tissue and adipokines in obesity-related inflammatory diseases. Mediators of inflammation, 2010. 2010.

24.Kissebah, A. H., et al., Relation of body fat distribution to metabolic complications of obesity. The Journal of Clinical Endocrinology \& Metabolism, 1982. 54(2): p. 254-260.

25.Krotkiewski, M., et al., Impact of obesity on metabolism in men and women. Importance of regional adipose tissue distribution. The Journal of clinical investigation, 1983. 72(3): p. 1150-1162.

26.Amato, M. C., et al., Visceral Adiposity Index: a reliable indicator of visceral fat function associated with cardiometabolic risk. Diabetes Care, 2010. 33(4): p. $920-2$.

27.Misra, A. and L. Khurana, Obesity-related non-communicable diseases: South Asians vs White Caucasians. International journal of obesity, 2011. 35(2): p. 167.

28.Snijder, M. B., et al., Associations of hip and thigh circumferences independent of waist circumference with the incidence of type 2 diabetes: the Hoorn Study. The American journal of clinical nutrition, 2003. 77(5): p. 1192-1197.

29.Tanko, L. B., et al., Peripheral adiposity exhibits an independent dominant antiatherogenic effect in elderly women. Circulation, 2003. 107(12): p. 16261631.

30.Czernichow, S., et al., Comparison of waist-to-hip ratio and other obesity indices as predictors of cardiovascular disease risk in people with type-2 diabetes: a prospective cohort study from ADVANCE. European Journal of Cardiovascular Prevention \& Rehabilitation, 2011. 18(2): p. 312-319.

31.Pagano, E. S., E. Spinedi, and J. J. Gagliardino, White adipose tissue and circadian rhythm dysfunctions in obesity: pathogenesis and available therapies. Neuroendocrinology, 2017. 104(4): p. 347-363.

32.Flegal, K. M., et al., Association of all-cause mortality with overweight and obesity using standard body mass index categories: a systematic review and meta-analysis. Jama, 2013. 309(1): p. 71-82.

33.Manu, P., et al., Dysmetabolic signals in "metabolically healthy" obesity. Obesity research \& clinical practice, 2012. 6(1): p. e9-e20.

34.Samocha-Bonet, D., et al., Insulin-sensitive obesity in humans-a 'favorable fat'phenotype? Trends in Endocrinology \& Metabolism, 2012. 23(3): p. 116-124.

35.Denis, G. V. and M. S. Obin, 'Metabolically healthy obesity': origins and implications. Molecular aspects of medicine, 2013. 34(1): p. 59-70.

36.Fan, H., et al., Abdominal obesity is strongly associated with cardiovascular disease and its risk factors in elderly and very elderly community-dwelling Chinese. Scientific reports, 2016. 6: p. 21521.

37.Després, J.-P., Abdominal obesity and cardiovascular disease: is inflammation the missing link? Canadian Journal of Cardiology, 2012. 28(6): p. 642-652.

38.Peer, N., K. Steyn, and N. Levitt, Differential obesity indices identify the metabolic syndrome in Black men and women in Cape Town: the CRIBSA study. Journal of Public Health, 2015. 38(1): p. 175-182.

39.Schmidt, F. M., et al., Inflammatory cytokines in general and central obesity and modulating effects of physical activity. PloS one, 2015. 10 (3): p. e0121971. 40.Després, J. P., Is visceral obesity the cause of the metabolic syndrome? Annals of medicine, 2006. 38(1): p. 52-63.

41.Despres, J.-P., et al., Abdominal obesity and the metabolic syndrome: contribution to global cardiometabolic risk. Arteriosclerosis, thrombosis, and vascular biology, 2008. 28(6): p. 1039-1049.

42.Bakir, M. A., K. Hammad, and L. Mohammad, Prevalence of obesity, central obesity, and associated socio-demographic variables in Syrian women using different anthropometric indicators. AnthropologicAl review, 2017. 80(2): p. 191-205.

43.Kruger, M. J. and T. A. Nell, The prevalence of the metabolic syndrome in a farm worker community in the Boland district, South Africa. BMC public health, 2017. 17(1): p. 61-61. 
44.Stewart, A., et al., International Standards for Anthropometric Assessment. Vol. 137. 2011.

45.De Onis, M. and J.-P. Habicht, Anthropometric reference data for international use: recommendations from a World Health Organization Expert Committee. The American journal of clinical nutrition, 1996. 64(4): p. 650-658.

46.Freedman, D. S. and A. A. Rimm, The relation of body fat distribution, as assessed by six girth measurements, to diabetes mellitus in women. American journal of public health, 1989. 79(6): p. 715-720.

47.Force, I. A. R. T., Type 2 diabetes clinical practice guidelines for Sub-Saharan Africa. Dar es Salaam: International Diabetes Federation Africa Region, 2006.

48.Amato, M. C., et al., Cut-off points of the visceral adiposity index (VAI) identifying a visceral adipose dysfunction associated with cardiometabolic risk in a Caucasian Sicilian population. Lipids in health and disease, 2011. 10(1): p. 183.

49.Organization, W. H., Waist circumference and waist-hip ratio: report of a WHO expert consultation, Geneva, 8-11 December 2008. 2011.

50.Finucane, M. M., et al., National, regional, and global trends in body-mass index since 1980: systematic analysis of health examination surveys and epidemiological studies with 960 country-years and 9. 1 million participants. The Lancet, 2011. 377(9765): p. 557-567.

51.Cois, A. and C. Day, Obesity trends and risk factors in the South African adult population. BMC obesity, 2015. 2(1): p. 42.

52.Nienaber-Rousseau, C., et al., Socio-demographic and lifestyle factors predict 5-year changes in adiposity among a group of black South African adults. International journal of environmental research and public health, 2017. 14(9): p. 1089.

53.Sartorius, B., et al., Rapidly increasing body mass index among children, adolescents and young adults in a transitioning population, South Africa, 200815. International journal of epidemiology, 2017.

54.Sahakyan, K. R., et al., Normal-weight central obesity: implications for total and cardiovascular mortality. Annals of internal medicine, 2015. 163(11): p. 827-835.

55.Owolabi, E. O., D. Ter Goon, and O. V. Adeniyi, Central obesity and normal-weight central obesity among adults attending healthcare facilities in Buffalo City Metropolitan Municipality, South Africa: a cross-sectional study. Journal of Health, Population and Nutrition, 2017. $36(1)$ : p. 54.

56.Knowles, K., et al., Waist circumference, body mass index, and other measures of adiposity in predicting cardiovascular disease risk factors among Peruvian adults. International journal of hypertension, 2011. 2011.

57.Lam, B.C. C., et al., Comparison of body mass index (BMI), body adiposity index (BAI), waist circumference (WC), waist-to-hip ratio (WHR) and waist-toheight ratio (WHtR) as predictors of cardiovascular disease risk factors in an adult population in Singapore. PloS one, 2015. 10(4): p. e0122985.

58.Rodríguez, A., et al., Visceral and subcutaneous adiposity: are both potential therapeutic targets for tackling the metabolic syndrome? Current pharmaceutical design, 2007. 13(21): p. 2169-2175.

59.Fontana, L., et al., Visceral fat adipokine secretion is associated with systemic inflammation in obese humans. Diabetes, 2007. 56(4): p. 1010-1013.

60.Tchernof, A. and J.-P. Després, Pathophysiology of human visceral obesity: an update. Physiological reviews, 2013. 93(1): p. 359-404.

61.Schlecht, l., et al., Relations of visceral and abdominal subcutaneous adipose tissue, body mass index, and waist circumference to serum concentrations of parameters of chronic inflammation. Obesity facts, 2016. 9(3): p. 144-157.

62.Despres, J., Intra-abdominal obesity: an untreated risk factor for Type 2 diabetes and cardiovascular disease. Journal of endocrinological investigation, 2006. 29(3): p. 77.

63.Dyer, A. R. and P. Elliott, The INTERSALT study: relations of body mass index to blood pressure. INTERSALT Co-operative Research Group. Journal of human hypertension, 1989. 3(5): p. 299-308.

64.DYER, A. R., et al., Body Mass Index Versus Height And Weight In Relation To Blood Pressure Findings For The 10,079 Persons In Tee Intersalt Study. American journal of epidemiology, 1990. 131(4): p. 589-596.

65.Leggio, M., et al., The relationship between obesity and hypertension: an updated comprehensive overview on vicious twins. Hypertension Research, 2017. 40(12): p. 947.

66.Rosa, E. C., et al., Visceral obesity, hypertension and cardio-renal risk: a review. Arquivos Brasileiros de Endocrinologia \& Metabologia, 2005. 49(2): p. 196204.

67.Esser, N., et al., Inflammation as a link between obesity, metabolic syndrome and type 2 diabetes. Diabetes research and clinical practice, 2014. 105(2): p. $141-150$.

68.Stępień, M., et al., Obesity indices and inflammatory markers in obese non-diabetic normo-and hypertensive patients: a comparative pilot study. Lipids in health and disease, 2014. 13(1): p. 29. 
69.Miller, M., Dyslipidemia and cardiovascular risk: the importance of early prevention. QJM: An International Journal of Medicine, 2009. $102(9)$ : p. 657-667. 70.Wang, H. and D.-Q. Peng, New insights into the mechanism of low high-density lipoprotein cholesterol in obesity. Lipids in health and disease, 2011. 10(1): p. 176.

71.Klug, E., et al., South African Dyslipidaemia Guideline Consensus Statement: A joint statement from the South African Heart Association (SA Heart) and the Lipid and Atherosclerosis Society of Southern Africa (LASSA). Journal of Endocrinology, Metabolism and Diabetes of South Africa, 2012. 17(3): p. 155-165.

72.Klop, B., J. Elte, and M. Cabezas, Dyslipidemia in obesity: mechanisms and potential targets. Nutrients, 2013. 5(4): p. 1218-1240.

73.Tomkin, G. and D. Owens, Diabetes and dyslipidemia: characterizing lipoprotein metabolism. Diabetes, metabolic syndrome and obesity: targets and therapy, 2017. 10: p. 333.

74.Stone, N. J., et al., 2013 ACC/AHA guideline on the treatment of blood cholesterol to reduce atherosclerotic cardiovascular risk in adults: a report of the American College of Cardiology/American Heart Association Task Force on Practice Guidelines. Journal of the American College of Cardiology, 2014. 63(25 Part B): p. 2889-2934.

75.Johnson, A.M. and J. M. Olefsky, The origins and drivers of insulin resistance. Cell, 2013. 152(4): p. 673-684.

76.Yusuf, S., et al., Effect of potentially modifiable risk factors associated with myocardial infarction in 52 countries (the INTERHEART study): case-control study. The lancet, 2004. 364(9438): p. 937-952.

77.Williams, K. J. and I. Tabas, Lipoprotein retention-and clues for atheroma regression. 2005, Am Heart Assoc.

78.Sakakura, K., et al., Pathophysiology of atherosclerosis plaque progression. Heart, Lung and Circulation, 2013. 22(6): p. 399-411.

79.Reiger, S., et al., Awareness, treatment, and control of dyslipidemia in rural South Africa: The HAALSI (Health and Aging in Africa: A Longitudinal Study of an INDEPTH Community in South Africa) study. PloS one, 2017. 12(10): p. e0187347.

80.Aleksandrova, K., D. Mozaffarian, and T. Pischon, Addressing the perfect storm: biomarkers in obesity and pathophysiology of cardiometabolic risk. Clinical chemistry, 2018. 64(1): p. 142-153.

81.Park, H. S., J. Y. Park, and R. Yu, Relationship of obesity and visceral adiposity with serum concentrations of CRP, TNF-a and IL-6. Diabetes research and clinical practice, 2005. 69(1): p. 29-35.

82.Monteiro, R. and I. Azevedo, Chronic inflammation in obesity and the metabolic syndrome. Mediators Inflamm, 2010. 2010.

83.Motala, A. A., et al., The prevalence of metabolic syndrome and determination of the optimal waist circumference cutoff points in a rural South African community. Diabetes care, 2011. 34(4): p. 1032-1037.

84.Zhao, D. and H. Liu, Adipose tissue dysfunction and the pathogenesis of metabolic syndrome. World Journal of Hypertension, 2013. 3(3): p. 18-26.

85.Weisberg, S. P., et al., Obesity is associated with macrophage accumulation in adipose tissue. The Journal of clinical investigation, 2003. 112(12): p. 17961808.

86.Bourlier, V., et al., Remodeling phenotype of human subcutaneous adipose tissue macrophages. Circulation, 2008. 117(6): p. 806.

87.Exley, M. A., et al., Interplay between the immune system and adipose tissue in obesity. Journal of Endocrinology, 2014. 223(2): p. R41-R48.

88.Lackey, D. E. and J. M. Olefsky, Regulation of metabolism by the innate immune system. Nature Reviews Endocrinology, 2016. 12(1): p. 15.

89.Cinti, S., et al., Adipocyte death defines macrophage localization and function in adipose tissue of obese mice and humans. Journal of lipid research, 2005. 46(11): p. 2347-2355.

90.Suganami, T., J. Nishida, and Y. Ogawa, A paracrine loop between adipocytes and macrophages aggravates inflammatory changes: role of free fatty acids and tumor necrosis factor a. Arteriosclerosis, thrombosis, and vascular biology, 2005. 25(10): p. 2062-2068.

91.Fuentes, E., et al., Mechanisms of chronic state of inflammation as mediators that link obese adipose tissue and metabolic syndrome. Mediators of inflammation, 2013. 2013.

92.Han, J. M. and M. K. Levings, Immune regulation in obesity-associated adipose inflammation. The Journal of Immunology, 2013. 191(2): p. 527-532.

93.Zheng, C., et al., Local proliferation initiates macrophage accumulation in adipose tissue during obesity. Cell death \& disease, $2016.7(3)$ : p. e2167.

94.Engin, A. B., Adipocyte-macrophage cross-talk in obesity, in Obesity and Lipotoxicity. 2017, Springer. p. 327-343.

95.Lesna, I. K., et al., Human adipose tissue accumulation is associated with pro-inflammatory changes in subcutaneous rather than visceral adipose tissue. Nutrition \& diabetes, 2017. 7(4): p. e264. 
96.Lebovitz, H. E., Insulin resistance-a common link between type 2 diabetes and cardiovascular disease. Diabetes, Obesity and Metabolism, 2006. 8(3): p. 237-249.

97.Vella, C. A., et al., Associations of insulin resistance with cardiovascular risk factors and inflammatory cytokines in normal-weight Hispanic women. Diabetes Care, 2013. 36(5): p. 1377-1383.

98.Jaganathan, R., R. Ravindran, and S. Dhanasekaran, Emerging role of adipocytokines in type 2 diabetes as mediators of insulin resistance and cardiovascular disease. Canadian journal of diabetes, 2018. 42(4): p. 446-456. e1.

99.Kahn, S. E., R. L. Hull, and K. M. Utzschneider, Mechanisms linking obesity to insulin resistance and type 2 diabetes. Nature, 2006. 444(7121): p. 840.

100.Lukic, L., et al., Hypertension in obese type 2 diabetes patients is associated with increases in insulin resistance and IL-6 cytokine levels: potential targets for an efficient preventive intervention. International journal of environmental research and public health, 2014. 11(4): p. 3586-3598.

101.Lamarche, B., et al., Fasting insulin and apolipoprotein B levels and low-density lipoprotein particle size as risk factors for ischemic heart disease. Jama, 1998. 279(24): p. 1955-1961.

\section{Tables}

Table 1. Prevalence based on anthropometrical indices

\begin{tabular}{|l|c|c|}
\hline & Normal weight & Overweight \\
\hline BMI $\left(\mathrm{kg} / \mathrm{m}^{2}\right)$ & $74.2 \%(\mathrm{n}=89)$ & $25.8 \%(\mathrm{n}=31)$ \\
\hline Waist to hip ratio & $57.5 \%(\mathrm{n}=69)$ & $42.5 \%(\mathrm{n}=51)$ \\
& & \\
\hline Waist circumference $(\mathrm{cm})$ & $42 \%(\mathrm{n}=50)$ & $58.3 \%(\mathrm{n}=70)$ \\
\hline Visceral Adiposity Index & $51.7 \%(\mathrm{n}=62)$ & $48.3 \%(\mathrm{n}=58)$ \\
\hline
\end{tabular}

Table 2: Summary of anthropometrical and physiological characteristics for the women according to anthropometric indices and subgroups.

\begin{tabular}{|c|c|c|c|c|c|c|c|c|c|c|c|}
\hline$\equiv$ & \multicolumn{3}{|c|}{ BMI } & \multicolumn{3}{|c|}{ W:H } & \multicolumn{3}{|c|}{ WC } & \multicolumn{2}{|r|}{ VAI } \\
\hline Parameters & $\begin{array}{l}\text { Normal } \\
(n=31)\end{array}$ & $\begin{array}{l}\text { Overweight } \\
\quad(n=89)\end{array}$ & P-value & $\begin{array}{l}\text { Normal } \\
(n=69)\end{array}$ & $\begin{array}{l}\text { At Risk } \\
(n=51)\end{array}$ & P-value & $\begin{array}{l}\text { Normal } \\
(n=50)\end{array}$ & $\begin{array}{l}\text { Overweight } \\
\quad(n=70)\end{array}$ & P-value & $\begin{array}{c}\text { Metabolically } \\
\text { healthy } \\
(\mathrm{n}=62)\end{array}$ & $\begin{array}{c}\text { Metabolically } \\
\text { unhealthy } \\
(n=58)\end{array}$ \\
\hline Age (years) & $\begin{array}{c}31[22 \\
-39]\end{array}$ & $\begin{array}{c}40[32- \\
48]\end{array}$ & $\mathrm{p}<0.0001$ & $\begin{array}{c}35 \\
{[28.0-} \\
45]\end{array}$ & $\begin{array}{c}40[30- \\
48]\end{array}$ & $\mathrm{p}<0.05$ & $\begin{array}{c}34.0 \pm \\
1.4\end{array}$ & $41.1 \pm 1.2$ & $\mathrm{p}<0.0001$ & $34[29-42]$ & $42[34-49]$ \\
\hline $\begin{array}{l}\text { Body Mass } \\
(\mathrm{kg})\end{array}$ & $\begin{array}{c}55.4 \\
{[51.7-} \\
60.4]\end{array}$ & $\begin{array}{c}79.5[70.5 \\
-94.1]\end{array}$ & $\mathrm{p}<0.0001$ & $\begin{array}{c}71.0 \pm \\
2.0\end{array}$ & $\begin{array}{c}83.5 \pm \\
3.1\end{array}$ & $\mathrm{p}<0.001$ & $\begin{array}{c}60.4 \\
{[54.0} \\
-69.1]\end{array}$ & $\begin{array}{c}86.5[74.8- \\
95.5]\end{array}$ & $\mathrm{p}<0.0001$ & $\begin{array}{c}69.3 \text { [59.6 - } \\
83.1]\end{array}$ & $\begin{array}{c}79.4[68.2- \\
83.1]\end{array}$ \\
\hline $\begin{array}{l}\mathrm{BMI} \\
\left(\mathrm{kg} / \mathrm{m}^{2}\right)\end{array}$ & $\begin{array}{c}23.0 \\
{[21.1-} \\
24.0]\end{array}$ & $\begin{array}{c}30.3[27.6- \\
37.7]\end{array}$ & $\mathrm{p}<0.0001$ & $\begin{array}{c}26.7 \\
{[23.7-} \\
31.7]\end{array}$ & $\begin{array}{c}31.0 \\
{[27.4-} \\
37.6]\end{array}$ & $\mathrm{p}=0.0002$ & $\begin{array}{c}24.4 \\
{[22.3} \\
-26.2]\end{array}$ & $\begin{array}{c}32.7[28.9- \\
38.6]\end{array}$ & $\mathrm{p}<0.0001$ & $\begin{array}{c}26.7[23.8- \\
32.5]\end{array}$ & $\begin{array}{c}30.1[27.1 \\
-37.0]\end{array}$ \\
\hline W:H & $\begin{array}{c}0.75 \pm \\
0.01\end{array}$ & $0.80 \pm 0.01$ & $\mathrm{p}<0.0001$ & $\begin{array}{c}0.74 \\
{[0.71-} \\
0.77]\end{array}$ & $\begin{array}{c}0.85 \\
{[0.82-} \\
0.89]\end{array}$ & $\mathrm{p}<0.0001$ & $\begin{array}{c}0.74 \\
{[0.71-} \\
0.77]\end{array}$ & $\begin{array}{c}0.82[0.77- \\
0.86]\end{array}$ & $\mathrm{p}<0.0001$ & $\begin{array}{c}0.75[0.71- \\
0.82]\end{array}$ & $\begin{array}{c}0.82[0.77- \\
0.86]\end{array}$ \\
\hline WC (cm) & $\begin{array}{c}70.0 \\
{[67.1-} \\
73.5]\end{array}$ & $\begin{array}{c}87.6[80.8- \\
97.3]\end{array}$ & $\mathrm{p}<0.0001$ & $\begin{array}{c}76.5 \\
{[71.4-} \\
84.5]\end{array}$ & $\begin{array}{c}89.8 \\
{[83.8-} \\
105.6]\end{array}$ & $\mathrm{p}<0.0001$ & $\begin{array}{c}72.6 \\
{[68.3-} \\
75.9] \\
\end{array}$ & $\begin{array}{c}89.9 \text { [84.5 - } \\
101.3]\end{array}$ & $\mathrm{p}<0.0001$ & $\begin{array}{c}76.4[71.6- \\
86.2]\end{array}$ & $\begin{array}{c}88.2[82.3- \\
100.5]\end{array}$ \\
\hline VAI & $\begin{array}{c}1.02 \\
{[0.68-} \\
1.54]\end{array}$ & $\begin{array}{c}1.95[1.23- \\
3.11]\end{array}$ & $\mathrm{p}<0.0001$ & $\begin{array}{c}1.32 \\
{[0.81-} \\
1.82]\end{array}$ & $\begin{array}{c}2.45 \\
{[1.45-} \\
3.42]\end{array}$ & $\mathrm{p}<0.0001$ & $\begin{array}{c}0.99 \\
{[0.72-} \\
1.59]\end{array}$ & $\begin{array}{c}2.39[1.44- \\
3.35]\end{array}$ & $\mathrm{p}<0.0001$ & $\begin{array}{c}1.08[0.75- \\
1.39]\end{array}$ & $\begin{array}{c}2.73[2.20- \\
4.08]\end{array}$ \\
\hline $\begin{array}{l}\text { SBP } \\
(\mathrm{mmHg})\end{array}$ & $\begin{array}{c}130 \\
{[110-} \\
140]\end{array}$ & $\begin{array}{c}140[120- \\
150]\end{array}$ & $\mathrm{p}=0.003$ & $\begin{array}{c}130 \\
{[120-} \\
145]\end{array}$ & $\begin{array}{c}130 \\
{[120-} \\
145]\end{array}$ & ns & $\begin{array}{c}130 \\
{[120} \\
-140]\end{array}$ & $\begin{array}{c}140[120- \\
156]\end{array}$ & $\mathrm{p}=0.004$ & $\begin{array}{c}130[110- \\
140]\end{array}$ & $\begin{array}{c}140[123- \\
160]\end{array}$ \\
\hline $\begin{array}{l}\text { DBP } \\
\text { (mmHg) }\end{array}$ & $\begin{array}{c}80[70 \\
-90]\end{array}$ & $\begin{array}{c}84[80 \text { - } \\
90]\end{array}$ & $\mathrm{p}=0.01$ & $\begin{array}{c}80[75- \\
90]\end{array}$ & $\begin{array}{c}80[80 \\
-90]\end{array}$ & ns & $\begin{array}{c}80[70 \\
-90]\end{array}$ & $\begin{array}{c}90 \text { [80 - } \\
99]\end{array}$ & $\mathrm{p}<0.001$ & $80[70-90]$ & $87[80-96]$ \\
\hline VAT $\%$ & $\begin{array}{c}61.5 \pm \\
0.9\end{array}$ & $71.3 \pm 0.7$ & $\mathrm{p}=0.001$ & $\begin{array}{c}65.3 \pm \\
0.8\end{array}$ & $\begin{array}{c}73.7 \pm \\
0.9\end{array}$ & $\mathrm{p}<0.0001$ & $\begin{array}{c}68.2 \pm \\
1.0\end{array}$ & $69.3 \pm 1.0$ & ns & $67.7 \pm 1.0$ & $69.8 \pm 1.1$ \\
\hline SAT $\%$ & $\begin{array}{c}38.5 \pm \\
0.9\end{array}$ & $28.7 \pm 0.7$ & $\mathrm{p}=0.001$ & $\begin{array}{c}34.7 \pm \\
0.8\end{array}$ & $\begin{array}{c}26.3 \pm \\
0.9\end{array}$ & $\mathrm{p}<0.0001$ & $\begin{array}{c}31.8 \pm \\
1.0\end{array}$ & $30.7 \pm 0.9$ & ns & $32.3 \pm 0.9$ & $30.2 \pm 1.1$ \\
\hline
\end{tabular}

Data is presented as mean \pm SEM for parametric data and median [IQR] for non-parametric data. T-tests (parametric data) or Mann-Whitney U test (nonparametric data) were employed for comparison between groups. $p<0.05$ was considered as statistically significant. 
Table 3: Metabolic blood parameters according to anthropometric indices.

\begin{tabular}{|c|c|c|c|c|c|c|c|c|c|c|c|}
\hline \multirow[b]{2}{*}{ Parameters } & \multicolumn{3}{|c|}{ BMI } & \multicolumn{3}{|c|}{ W:H } & \multicolumn{3}{|c|}{ WC } & \multicolumn{2}{|r|}{ VAI } \\
\hline & $\begin{array}{l}\text { Normal } \\
(n=31)\end{array}$ & $\begin{array}{l}\text { Overweight } \\
\quad(n=89)\end{array}$ & P-value & $\begin{array}{l}\text { Normal } \\
(n=69)\end{array}$ & $\begin{array}{l}\text { At Risk } \\
(n=51)\end{array}$ & P-value & $\begin{array}{l}\text { Normal } \\
(n=50)\end{array}$ & $\begin{array}{l}\text { Overweight } \\
\quad(n=70)\end{array}$ & P-value & $\begin{array}{c}\text { Metabolically } \\
\text { healthy } \\
(n=62)\end{array}$ & $\begin{array}{c}\text { Metabolically } \\
\text { unhealthy } \\
(n=58)\end{array}$ \\
\hline $\begin{array}{l}\text { L.DL-c } \\
\text { (mmol/L) }\end{array}$ & $\begin{array}{c}2.54 \pm \\
0.13\end{array}$ & $2.98 \pm 0.11$ & $\mathrm{p}<0.01$ & $\begin{array}{c}2.67 \pm \\
0.12\end{array}$ & $\begin{array}{c}3.13 \pm \\
0.14\end{array}$ & $\mathrm{p}<0.05$ & $\begin{array}{c}0.78 \\
{[0.64-} \\
1.05]\end{array}$ & $\begin{array}{c}1.48[1.05- \\
2.08]\end{array}$ & $\mathrm{p}=0.0002$ & $2.65 \pm 0.11$ & $3.13 \pm 0.15$ \\
\hline $\begin{array}{l}\text { HDL-c } \\
\text { (mmol/L) }\end{array}$ & $\begin{array}{c}1.30 \\
{[1.10-} \\
1.60]\end{array}$ & $\begin{array}{c}1.10[0.90- \\
1.30]\end{array}$ & $\mathrm{p}<0.01$ & $\begin{array}{c}1.20 \\
{[1.00-} \\
1.5]\end{array}$ & $\begin{array}{c}1.1[0.9 \\
-1.3]\end{array}$ & $\mathrm{p}<0.05$ & $\begin{array}{l}1.30 \\
{[1.00-} \\
1.60]\end{array}$ & $\begin{array}{c}1.10[0.90- \\
1.30]\end{array}$ & $\mathrm{p}=0.0023$ & $\begin{array}{c}1.3[1.1- \\
1.6]\end{array}$ & $1[0.9-1.2]$ \\
\hline $\begin{array}{l}\text { Non-HDL-c } \\
(\mathrm{mmol} / \mathrm{L})\end{array}$ & $\begin{array}{c}2.97 \pm \\
0.15\end{array}$ & $3.58 \pm 0.12$ & $\mathrm{p}=0.002$ & $\begin{array}{c}3.17 \pm \\
0.13\end{array}$ & $\begin{array}{c}3.77 \pm \\
0.15\end{array}$ & $\mathrm{p}<0.01$ & $\begin{array}{c}1.34 \pm \\
0.06\end{array}$ & $\begin{array}{l}3.787 \pm \\
0.13\end{array}$ & $\mathrm{p}<0.0001$ & $3.11 \pm 0.12$ & $3.80 \pm 0.16$ \\
\hline $\begin{array}{l}\text { TG } \\
(\mathrm{mmol} / \mathrm{L})\end{array}$ & $\begin{array}{c}0.78 \\
{[0.63-} \\
1.0]\end{array}$ & $\begin{array}{c}1.25[0.87- \\
1.78]\end{array}$ & $\mathrm{p}<0.0001$ & $\begin{array}{c}0.85 \\
{[0.69-} \\
1.25]\end{array}$ & $\begin{array}{l}1.54 \\
{[1.11-} \\
2.22]\end{array}$ & $\mathrm{p}<0.0001$ & $\begin{array}{c}0.78 \\
{[0.64-} \\
1.05]\end{array}$ & $\begin{array}{c}1.48[1.05- \\
2.08]\end{array}$ & $\mathrm{p}<0.0001$ & $\begin{array}{c}0.78[0.64- \\
0.97]\end{array}$ & $\begin{array}{c}1.68[1.42- \\
2.35]\end{array}$ \\
\hline $\begin{array}{l}\text { TC } \\
\text { (mmol/L) }\end{array}$ & $\begin{array}{c}4.35 \pm \\
0.17\end{array}$ & $4.75 \pm 0.14$ & ns & $\begin{array}{c}4.44 \pm \\
0.14\end{array}$ & $\begin{array}{c}4.92 \pm \\
0.17\end{array}$ & $\mathrm{p}<0.05$ & $\begin{array}{c}4.26 \pm \\
0.16\end{array}$ & $4.92 \pm 0.14$ & $\mathrm{p}=0.0023$ & $4.45 \pm 0.14$ & $4.90 \pm 0.17$ \\
\hline TC:HDL-c & $\begin{array}{c}3.32 \pm \\
0.16\end{array}$ & $4.19 \pm 0.12$ & $\mathrm{p}<0.0001$ & $\begin{array}{c}3.62 \pm \\
0.12\end{array}$ & $\begin{array}{c}4.43 \pm \\
0.15\end{array}$ & $\mathrm{p}<0.0001$ & $\begin{array}{c}3.30 \pm \\
0.13\end{array}$ & $4.44 \pm 0.12$ & $\mathrm{p}<0.0001$ & $3.41 \pm 0.10$ & $4.60 \pm 0.14$ \\
\hline $\begin{array}{l}\text { Glucose } \\
(\mathrm{mmol} / \mathrm{L})\end{array}$ & $\begin{array}{c}4.6 \\
{[4.3} \\
-5.0]\end{array}$ & $\begin{array}{c}4.7[4.4- \\
5.8]\end{array}$ & ns & $\begin{array}{c}4.6 \\
{[4.3-} \\
5.1]\end{array}$ & $\begin{array}{c}5.2 \\
{[4.5-} \\
6.5]\end{array}$ & $\mathrm{p}=0.006$ & $\begin{array}{c}4.6 \\
{[4.2-} \\
5.0]\end{array}$ & $\begin{array}{c}4.9[4.5- \\
6.2]\end{array}$ & $\mathrm{p}<0.01$ & $\begin{array}{c}4.6[4.1- \\
5.0]\end{array}$ & $\begin{array}{c}4.9[4.5- \\
6.6]\end{array}$ \\
\hline $\begin{array}{l}\text { Insulin } \\
\text { (mIU/L) }\end{array}$ & $\begin{array}{l}10.5 \\
{[5.9-} \\
21.5]\end{array}$ & $\begin{array}{c}16.4[8.3- \\
31.7]\end{array}$ & ns & $\begin{array}{l}13.5 \\
{[6.8-} \\
22.4]\end{array}$ & $\begin{array}{l}17.0 \\
{[9.3-} \\
36.5]\end{array}$ & ns & $\begin{array}{l}10.1 \\
{[5.8-} \\
17.5]\end{array}$ & $\begin{array}{c}18.3[9.9- \\
35.8]\end{array}$ & $\mathrm{p}=0.0002$ & $\begin{array}{c}12.6[6.2- \\
22.8]\end{array}$ & $\begin{array}{c}16.7[9.5- \\
35.1]\end{array}$ \\
\hline
\end{tabular}

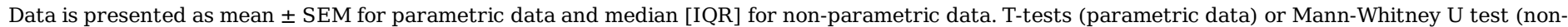
parametric data) were employed for comparison between groups. $p<0.05$ was considered as statistically significant.

\section{Figures}


A

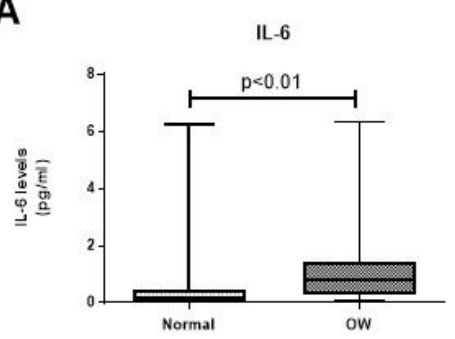

C

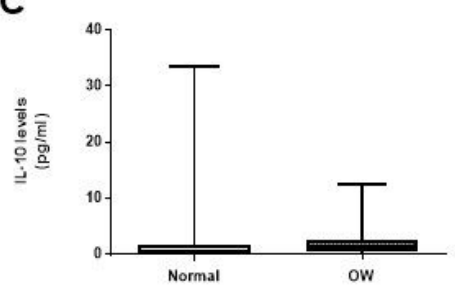

E

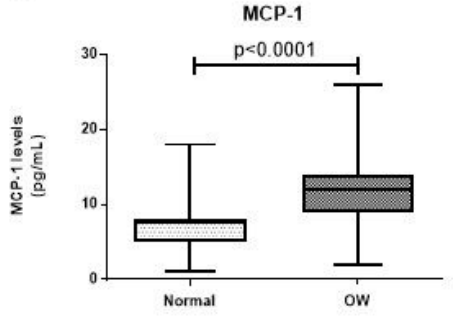

B

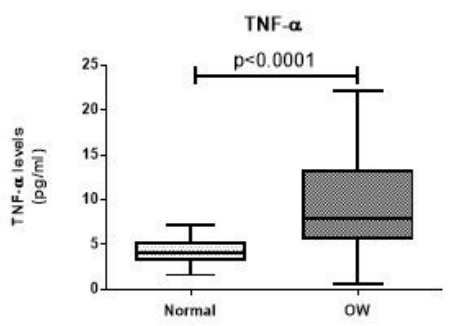

D

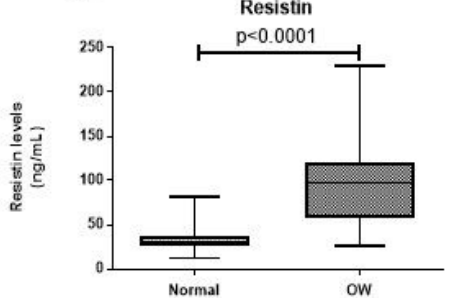

\section{Figure 1}

Inflammatory cytokine concentrations of participants classified as normal or overweight, based on BMI cut-off values (WHO. 1995), including (A) Interleukin-6, (B) tumor necrosis factor-a, (C) Interleukin-10, (D) monocyte chemoattractant protein-1, and (E) resistin. A p $<0.05$ was considered as statistically significant. 
A
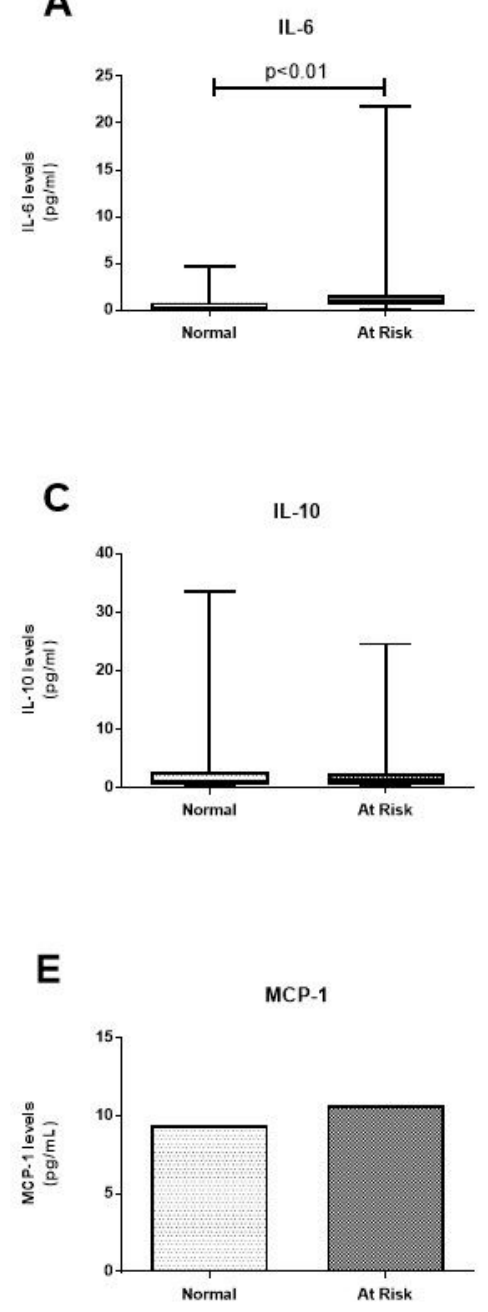

B
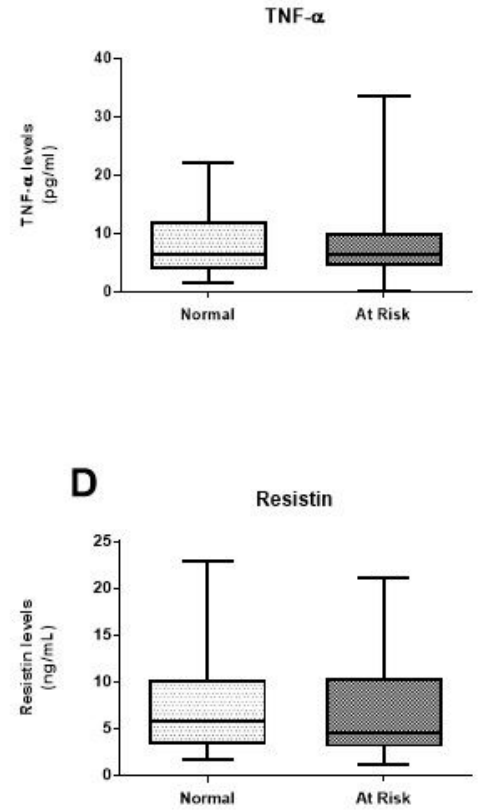

\section{Figure 2}

Inflammatory cytokine concentrations of participants classified as normal or at risk, based on W:H cut-off values for CVD risk (Freedman et al., 1989), including (A) Interleukin-6, (B) tumor necrosis factor-a, (C) Interleukin-10, (D) monocyte chemoattractant protein-1, and (E) resistin. A p $<0.05$ was considered as statistically significant. 
A

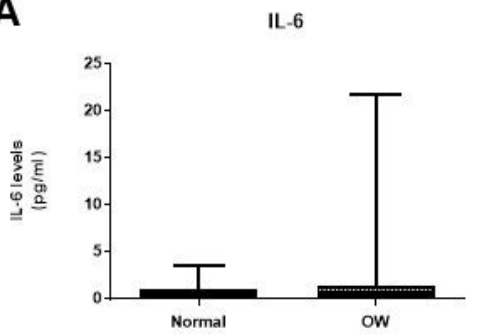

C

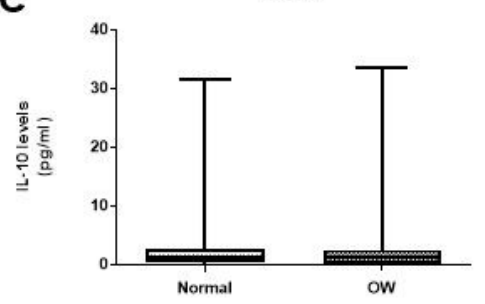

E

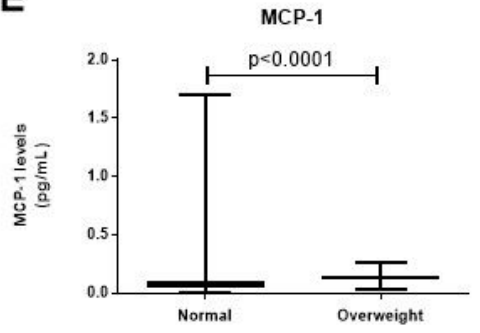

B

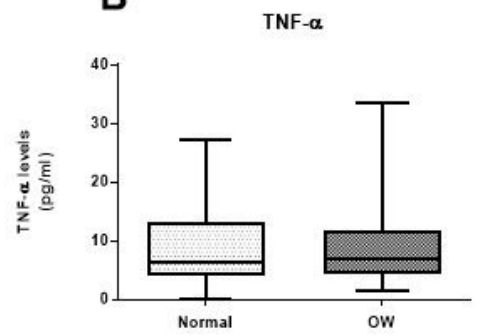

D

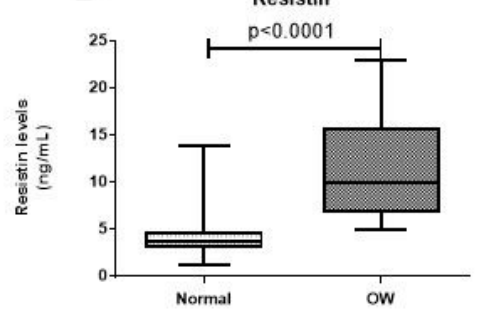

\section{Figure 3}

Inflammatory cytokine concentrations of participants classified as normal or overweight (centrally obese), based on WC cut-off values (IDF Clinical Guidelines Task Force, 2006), including (A) Interleukin-6, (B) tumor necrosis factor-a, (C) Interleukin-10, (D) monocyte chemoattractant protein-1, and (E) resistin. A p<0.05 was considered as statistically significant. 

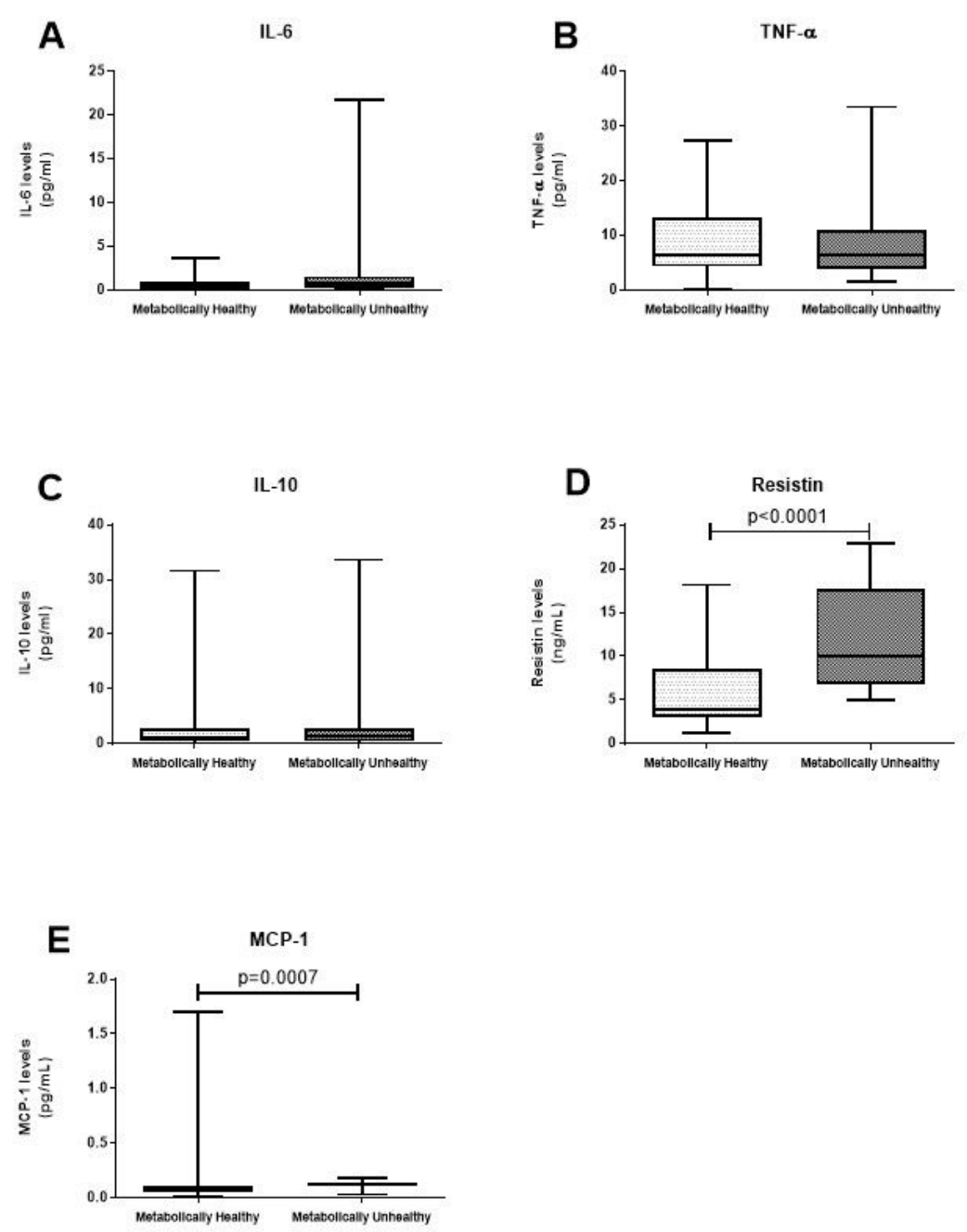

\section{Figure 4}

Inflammatory cytokine concentrations of participants classified as metabolically healthy or unhealthy, based on VAl cut-off values (Du et al., 2015; Dong et al., 2017), including (A) Interleukin-6, (B) tumor necrosis factor-a, (C) Interleukin-10, (D) monocyte chemoattractant protein-1, and (E) resistin. A p<0.05 was considered as statistically significant.

\section{Supplementary Files}

This is a list of supplementary files associated with this preprint. Click to download.

- eq3.jpg

- eq12.jpg 